\title{
The effect of information feedback upon psychophysical judgments
}

\author{
Richard C. Atkinson, STANFORD UNIVERSTY; Edward C. Carterette, UNIVERSITY OF \\ CALIFORNIA, LOS ANGELES; and Ronald A. Kinchla, AMES RESEARCH CENTER
}

\begin{abstract}
Abstraet
An analysis was made of the role of presentation schedules and information feedback on performance in a forced-choice signal detection task. The experimental results indicate that information feedback facilitates performance, but only for certain presentation schedules.
\end{abstract}

\section{Introduction}

The present study was designed to assess performance in a signal detection task under two conditions of information feedback. In the I-condition, $\mathrm{S}$ was told on each trial whether his detection response was correct or incorrect; in the $\tilde{\mathrm{I}}$-condition $\mathrm{S}$ was given no feedback regarding the correctness of his reponse. The task involved a 2-response, forced-choice auditory detection problem. On each trial 2 temporal intervals were defined and $\mathrm{S}$ was required to report which interval he believed contained the signal; i. e., in one interval a tone burst in a background of white noise was presented, while the other interval contained only white noise. A trial will be denoted as $\mathrm{S}_{1}$ or $\mathrm{S}_{2}$, depending on whether the signal was embedded in the lst or 2nd interval; the S's response will be denoted $A_{1}$ or $A_{2}$ to indicate which interval he reported contained the signal.

The probability of an $\mathrm{s}_{1}$ trial will be denoted as $\gamma$. In this study two values of $\gamma$ were used (.50 and .75) and, as indicated above, two conditions of information feedback. Thus there were 4 experimental conditions (50I, 50 $\tilde{\mathrm{I}}, 75 \mathrm{I}, 75 \tilde{\mathrm{I}})$; each $\mathrm{S}$ was run under all 4 conditions.

\section{Method}

Gaussian noise was presented binaurally in S's headphones throughout a test session and the signal was a 1000-cps sinusoid tone; the tone was presented for 100 msec. including equal fall and rise times of $20 \mathrm{msec}$. The ratio of signal energy to noise power in a unit bandwidth was 2.9 , and was constant throughout the study. The $\mathrm{S}$ was seated before a stimulus display board. On each trial a red warning light was flashed for $100 \mathrm{msec}$. Two amber lights then came on successively each for $1 \mathrm{sec}$; these lights defined the 2 observation intervals. The onset of the signal occurred $500 \mathrm{msec}$. after the onset of one of the observation intervals. After the second amber light went off, $S$ indicated his response by pressing 1 of 2 wand switches under cards reading " 1 st interval" and "2nd interval." For the I-condition a green light flashed on above the correct response key after S's response; the green light was omitted in the $\widetilde{I}$-condition. Each trial lasted $6 \mathrm{sec}$.
The Ss were 12 male college students with normal hearing. They were run for two practice sessions followed by 20 test sessions. Test sessions were run on consecutive days, 350 trials/day. Each day $\mathrm{S}$ ran on 1 of the 4 experimental conditions; in successive 4-day blocks $\mathrm{S}$ ran one day on each of the 4 experimental conditions in a random order. Thus, over 20 days each of the experimental conditions was repeated 5 times.

\section{Results and Diseussion}

Figure 1 presents the proportion of $\mathrm{A}_{1}$ responses on $\mathrm{S}_{1}$ trials as a function of 50-trial blocks within each of the 5 replications. Note that the $\operatorname{Pr}\left(\mathrm{A}_{1} \mid \mathrm{s}_{1}\right)$ curve for the $75 \tilde{\mathrm{I}}$-condition lies above the curve for the 75I-condition; however, for the 50 schedules the information variable appears to have no effect.

In the theory of signal detection proposed by Atkinson (1963) predictions are made concerning the relation between presentation schedules and information feedback. The details of these predictions are presented in Atkinson, Carterette and Kinchla (1963). For firstorder statistics the qualitative predictions are

Information
$\operatorname{Pr}\left(A_{1} \mid S_{1}\right) \geqslant \frac{\text { No-Information }}{\operatorname{Pr}\left(A_{1} \mid S_{1}\right)}$
$\operatorname{Pr}\left(A_{2} \mid S_{2}\right) \leqslant \operatorname{Pr}\left(A_{2} \mid S_{2}\right)$
$\operatorname{Pr}\left(A_{1}\right)$

if $\gamma>1 / 2$; equalities hold when $\gamma=1 / 2$. To evaluate these predictions we estimated the appropriate probabilities for individual Ss over the last 250 trials of

$$
\operatorname{Pr}\left(A_{1} \mid S_{1}\right)
$$

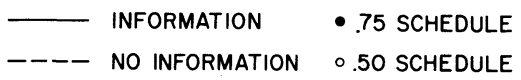

$1.00-$

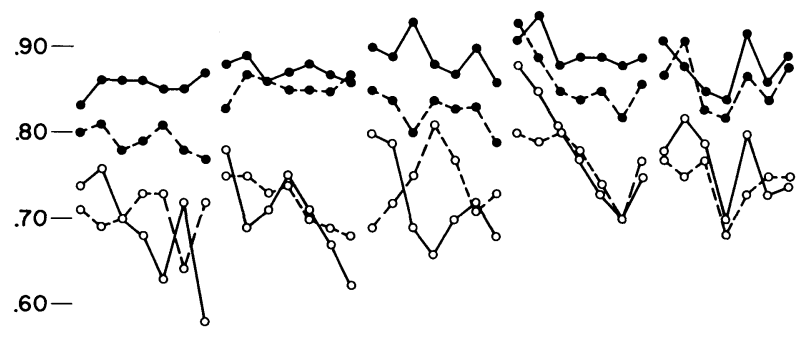

$.50-$

Fig. 1. Proportion of $A_{1}$ responses on $S_{1}$ trials. 
replications 2 through 5 . The means of these estimates for each experimental condition are as follows:

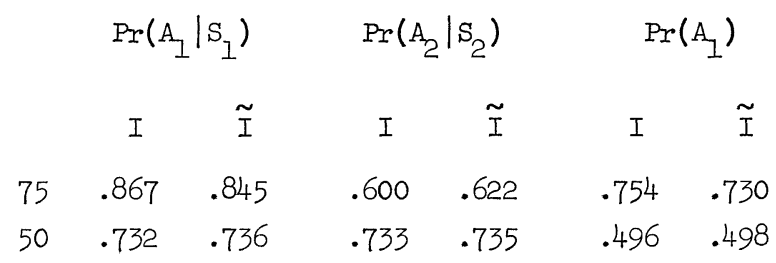

In all cases the predicted relations are reflected in the data.

Another prediction of the theory (under experimental conditions not involving payoffs) is that $\operatorname{Pr}\left(\mathrm{A}_{1}\right)$ should approach $\gamma$ in the information case. As indicated above, this "matching', prediction is well supported by both the 50 and 75 schedules. Related to this result are predictions about trial-to-trial sequential effects. In general the predicted sequential effects are supported by our data. For example we predict:

$\operatorname{Pr}\left(\mathrm{A}_{\mathrm{i}, \mathrm{n}} \mid \mathrm{S}_{\mathrm{i}, \mathrm{n}} \mathrm{S}_{\mathrm{i}, \mathrm{n}-1}\right)>\operatorname{Pr}\left(\mathrm{A}_{\mathrm{i}, \mathrm{n}} \mid \mathrm{S}_{\mathrm{i}, \mathrm{n}} \mathrm{S}_{\mathrm{j}, \mathrm{n}-1}\right)$ where $\mathrm{i} \neq \mathrm{j}$ and $\mathrm{n}$ denoted the trial number. Inspection of the group data indicates that these quantities are properly ordered for all 4 experimental conditions. Also, we predict that $\operatorname{Pr}\left(\mathrm{A}_{1, \mathrm{n}} \mid \mathrm{S}_{1, \mathrm{n}} \mathrm{S}_{1, \mathrm{n}-1} \ldots \mathrm{S}_{1, \mathrm{n}-\mathrm{x}}\right)$ should increase as $x$ increases; i.e., the probability of $A_{1}$ to $S_{1}$ should increase as the string of previous $S_{1}$ trials increases. This "positive recency" effect was clearly evident in our data.

References

ATKINSON, R. C. A variable sensitivity theory of signal detection. Psychol. Rev., 1963, 70, 91-106.

ATKINSON, R. C., CARTERETTE, E. C., \& KINCHLA, R. A. Sequential phenomena in psychophysical judgments. Inst. Radio Engineers Trans. on Information Theory, IT-8, S155-162. 